\title{
TINJAUAN \\ KONSERVASI SUMBER DAYA ASPAL BUTON
}

\author{
Denni Widhiyatna, R. Hutamadi, Sutrisno \\ Kelompok Program Penelitian Konservasi
}

SARI

Aspal Buton merupakan satu-satunya cebakan aspal alam di Indonesia. Aspal Buton telah ditambang oleh PT. Sarana Karya, namun dalam perkembangannya bahan galian ini menghadapi kendala pemasaran, antara lain akibat adanya produk aspal residu dari pengolahan minyak bum. Jenis ini lebih mudah diperoleh dan murah sehingga memiliki keunggulan dalam pengunaannya.

Cadangan aspal buton yang masih tertinggal tercatat sebanyak 179,1 juta ton dengan sumber daya hipotetik minyak dalam aspal sebesar 10.577.646.000 liter. Upaya memodifikasi produk telah dilakukan oleh pihak terkait seperti membuat BGA (Buton Granule Agregat) dalam beberapa ukuran tertentu, namun belum belum berhasil meningkatkan daya saing aspal buton di pasaran.

Batugamping sebagai batuan induk dari endapan aspal buton merupakan bahan galian lain yang perlu dikaji lebih jauh kuantitas dan kualitasnya selama kegiatan penambangan aspal. Upaya penanganan batugamping perlu direncanakan dengan baik dalam rangka mengoptimalkan pemanfaatan seluruh potensi cebakan yang ada.

\section{ABSTRACT}

Asphalt of Buton is just natural asphalt deposit in Indonesia. This asphalt has been mined by PT.Sarana Karya (Persero) but in its development of this content asphalt has marketing constraint because of weakness promotion and in case of presence of asphalt residu from petroleum processing. This type of asphalt is relative easier to be obtained and cheap, though it has speciality for quality.

The remaining reserves of asphalt buton are recorded 179.1 million tones with hypothetical resources of 10,577,646,000 liters oil. Modification effort of product has been done by related parties in making Buton Granule Agregat (BGA) of certain scale, but it has not successfully to increase competitiveness of the asphalt marketing

Limestone as a host rock of this asbuton deposit is an other material that need to be investigated both its quantity and quality during mining activity of asphalt. Exploiting effort of limestone also has to be planned carefully in order to optimalize utilization the existing potential deposits.

\section{PENDAHULUAN}

Lokasi sumber daya aspal terletak di Pulau Buton, secara administratif termasuk ke dalam Kabupaten Buton, Provinsi Sulawesi Tenggara. (Gambar 1).

Sumber daya aspal alam di Pulau Buton, Provinsi Sulawesi Tenggara merupakan satu-satunya endapan aspal alam di Indonesia. Selain di Indonesia, endapan aspal alam terdapat di Kepulauan Trinidad, Albania dan Irak yang dipergunakan untuk pelapis jalan, atap bangunan, mastic flooring, campuran paving dan campuran cat.

Aspal alam di Pulau Buton ini telah diketahui sejak awal abad ke-20. Penyelidikan pertama kali dilakukan oleh Elbert tahun 1909. Kemudian tahun 1922-1930 oleh Departemen Tambang Pemerintahan Belanda di Hindia Timur. Pada Tahun 1926 aspal Buton dikerjakan oleh N.V. Meijnbouwen Cultuur Maatscappij Boeton sampai terjadinya perang Pasific atas dasar kerja borongan untuk pemerintah sampai tahun 1954. Sejak itu, pengusahaan aspal dikelola oleh Bagian Butas, Kementrian Pekerjaan Umum. Tahun 1962 didirikan Perusahaan Aspal Negara (PAN) sesuai dengan PP No.195 Tahun 1961 yang mengusahakan aspal alam lebih lanjut. Kemudian, berdasarkan PP No.3 Tahun 1984, PAN dialihkan menjadi PT. Sarana Karya.

Endapan aspal pada beberapa lokasi lapangan di Kecamatan Pasarwajo, Kabupaten Buton terdapat pada batuan induk yang berupa batugamping dan napal (Gambar 2 dan 4).

Aspal Buton dapat untuk penggunaan langsung pada pembuatan pelapis jalan. Sejalan dengan kenaikan harga minyak dunia yang sangat tinggi, memberikan peluang untuk memanfaatkan aspal untuk diolah menghasilkan minyak. Sehingga potensi nilai tambah yang dihasilkan dapat lebih optimal dibandingkan untuk penggunaan langsung.

Selain sumber daya aspal, batuan induk berupa batugamping yang akan ikut tergali dalam penambangan berpeluang untuk diusahakan sebagai by product. 


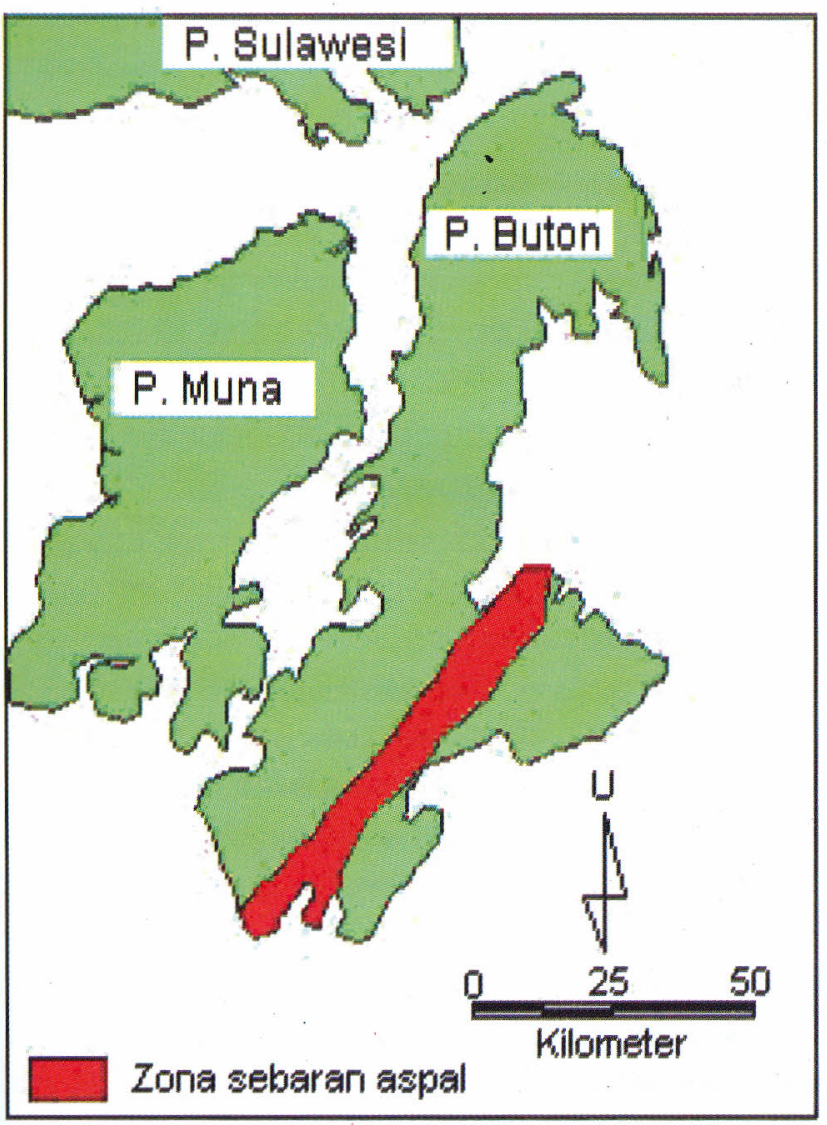

Gambar 1. Zona sebaran endapan Aspal di Pulau Buton

Geologi

Secara regional daerah kegiatan termasuk bagian dari Anjungan Tukang Besi Buton. Pada Trias Akhir hingga Jura Akhir berturut turut diendapkan batuan sedimen Formasi Winto, Formasi Ogena dan Formasi Rumu. Selanjutnya antara Kapur Akhir hingga Paleosen diendapkan sedimen laut dalam. Formasi Tobelo tidak selaras diatas Formasi-Formasi yang lebih tua. Pada Zaman Tersier kedalam cekungan Miosen diendapkan batuan sedimen dari Anggota Batugamping Formasi Tondo dan Formasi Sampolakosa. Kedua Formasi ini diduga menjemari dan berumur Miosen. Pada Akhir Tersier diendapkan Formasi Sampolakosa dalam lingkungan pengendapan neritik batial. Sedimentasi cekungan Tersier di daerah ini diakhiri dengan diendapkannya Formasi Wapulaka dan Aluvium pada Zaman Kuarter (Gambar 3).

Peristiwa tektonik yang terjadi pada anjungan Buton Tukangbesi setidaknya terjadi sebanyak tiga kali. Ketiganya turut berperan dalam pembentukan tatanan stratigrafi dan struktur di daerah ini. Struktur geologi yang berkembang terdiri dari antiklin, sinklin, sesar anjak, sesar normal dan sesar geser mendatar. Sesar-sesar utama yang terjadi umumnya mempunyai arah sejajar dengan arah memanjangnya tubuh batuan Pra Tersier dan sumbu cekungan sedimen Miosen.

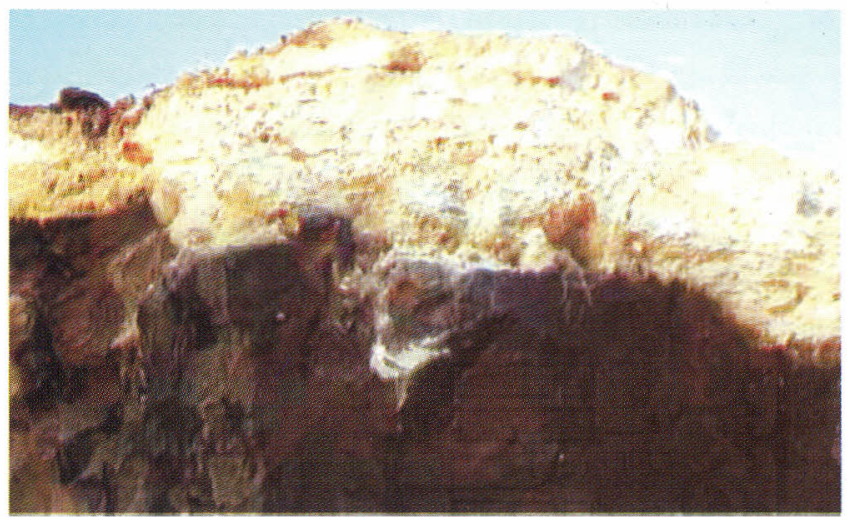

Gambar 2. Aspal (hitam) berada pada batuan induk batugamping (Tobing, 2004).

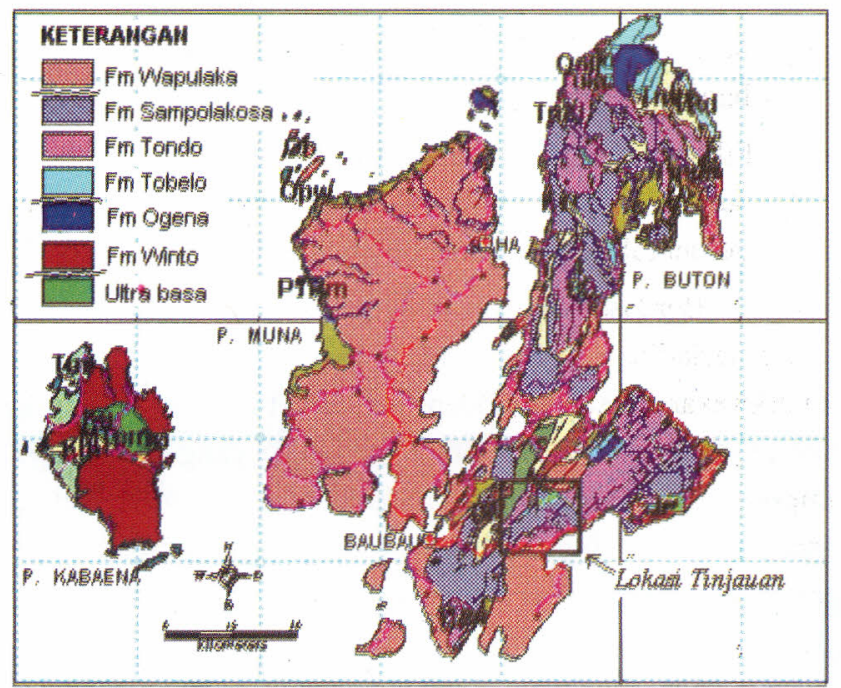

Gambar 3. Peta geologi Daerah Lembar Buton

Kegiatan tektonik pada Plio-Plistosen mengakibatkan terlipatnya kembali batuan yang lebih tua (Pra Pliosen) dan menggiatkan kembali sesar-sesar yang telah terbentuk sebelumnya (Sikumbang dkk, 1995).

Daerah penambangan Kabungka merupakan zona antiklinal yang disebut Winto Antiklinal, di bagian atas telah terkikis atau tererosi. Pada umumnya aspal buton ditemukan di puncak atau lereng antiklinal tersebut. Batuan penyusun Daerah Kabungka terdiri dari lima lapisan, yaitu lapisan Winto berumur Trias Atas; lapisan Ogene berumur Yura Bawah, lapisan Tobelo berumur Kapur, lapisan Tondo berumur Neogen Bawah, lapisan Sampolakosa berumur Neogen Atas.

Dari kelima lapisan ini, aspal hanya didapatkan pada batuan gamping dan napal Sampolakosa yang mempunyai kadar bitumen lebih tinggi karena batuan tersebut mempunyai banyak pori.

Mekanisme terjadinya aspal alam hinga kini belum diketahui dengan pasti, beberapa teori cara terbentuknya aspal alam, antara lain menurut Abdul Rosyid, 1996 sebagai berikut : 
a. Cara aliran (overflow) terjadi dalam tiga bentuk:

Spring, cairan aspal yang terbentuk dalam bumi muncul ke permukaan melalui celah, rekahan dan patahan.

Lake, aspal cair mengalir ke permukaan bumi melalui celah atau patahan kemudian mengendap dalam cekungan.

Seepage, aspal yang terdapat dalam batuan, kemudian mengalir ke bagian yang lebih rendah disebabkan tekanan material di sekitarnya atau karena panas matahari.

b. Impregnasi aspal dalam batuan (impregnating rock), aspal yang cair mengalir dan masuk pada pori-pori batuan yang dilaluinya, sehingga bersatu dengan batuan di mana aspal itu mengalir.

c. Filling vein, aspal yang cair mengalir melalui patahan dan akhirnya mengisi patahan tersebut hingga berbentuk seperti urat(vein).

Berdasarkan pengamatan dan pendapat beberapa pakar, terjadinya aspal yang berada di daerah Kabungka diperkirakan merupakan hasil dari impregnasi aspal cair ke dalam batuan di sekelilingnya atau yang dilaluinya. Impregnasi tersebut berkisar antara $1 \%$ sampai $40 \%$. Batuan yang berkadar bitumen antara 10\% hingga 40\% pada umumnya membentuk sheet structure, yaitu lapisan aspal dengan ketebalan kecil menyebar luas ke seluruh batuan sampingnya (country rock) namun belum diketahui hubungan lapisan aspal yang terdapat pada masing-masing lapangan. Gejala yang umum terdapat dari lapisan aspal ini adalah pembajian (wedging out) seperti yang diperlihatkan pada gambar 6 dan 7 .

Terjadinya aspal di Buton Selatan dibatasi zone patahan sepanjang bagian timur sisi Lawele graben, sedangkan lainnya mengarah ke timur laut barat daya. Patahan juga ditemukan di timur graben Lawele dan pegunungan Lawele (patahan Kamaru dan patahan Ondola).

\section{SUMBER DAYAASPAL BUTON}

Berdasarkan data PT. Sarana Karya, potensi aspal buton (asbuton) berjumlah sekitar 184 juta ton dengan kadar aspal $1535 \%$. Secara umum keterdapatan aspal buton terletak hanya antara 1,5 - 10 meter di bawah permukaan tanah. Lokasi aspal buton ini terdapat pada lima daerah yang dianggap ekonomis yaitu Waisiu, Kabungka, Winto, Wariti dan Lawele (Tabel 1), meliputi areal seluas 70.000 Ha yang membujur dari Teluk Sampolawa di sebelah selatan sampai Teluk Lawele di sebelah utara dalam suatu graben di selatan.

Saat ini aspal buton telah dikelola oleh PT. Sarana Karya dengan kuasa pertambangan eksploitasi aspal mulai berlaku tanggal 1 januari 1991 s/d 1 januari 2001 dengan wilayah konsesi seluas 8.000 Ha dengan produksi kurang dari 500 ribu ton per tahun.

Tabel 1. Estimasi cadangan aspal Buton pada daerah konsesi PT. Sarana Karya

\begin{tabular}{|c|l|r|c|}
\hline No. & \multicolumn{1}{|c|}{ Lokasi } & $\begin{array}{c}\text { Cadangan } \\
\text { (ton) }\end{array}$ & $\begin{array}{c}\text { Kadar Aspal } \\
(\%)\end{array}$ \\
\hline 1 & Waisiu & 100.000 & \pm 35 \\
\hline 2 & Kabungka & 60.000 .000 & $15-35$ \\
\hline 3 & Winto & 3.200 .000 & $25-35$ \\
\hline 4 & Wariti & 600.000 & \pm 30 \\
\hline 5 & Lawele & 100.000 .000 & $15-30$ \\
\hline
\end{tabular}

Data cadangan berdasarkan hasil pengumpulan data-data pemboran eksplorasi yaitu sebesar 184 juta ton, sedangkan jumlah produksi dari sejak tahun 1926 sampai 2002 sekitar 4,9 juta ton, hal ini menunjukkan bahwa sisa cadangan relatif masih cukup besar.

Sebagai contoh pada penampang lapangan Galababi (Gambar 6) di daerah Winto terlihat jelas endapan aspal yang berupa lensa lensa dimana keterdapatannya tidak menyambung dan ketebalan lapisan aspalnya pun bervariasi antara $213 \mathrm{~m}$. Ketebalan lapisan tanah penutup relatif sangat tipis sekitar $1 \mathrm{~m} 6 \mathrm{~m}$.

Penambangan yang dilakukan baru mencapai kedalaman $210 \mathrm{~m}$, sehingga dapat diperkirakan masih cukup tebal lapisan endapan aspal yang belum ditambang, kondisi ini diperlihatkan pada Gambar 6 dan 7 yang memperlihatkan penampang vertikal hasil pemboran dan penambangan yang masih menyisakan cadangan aspal yang relatifbesar.

\section{KEGUNAANASPAL BUTON}

Aspal buton dapat digunakan antara lain untuk :

- Perkerasan/lapisan permukaan sebagai pengganti aspal minyak.

- Asbuton Tile(Tegel Asbuton)

- Block Asbuton antara lain untuk trotoar.

- Mengekstraksi bitumen dari asbuton.

- Melapis bendung/embung agar kedap air.

Asbuton cocok untuk konstruksi berat karena aspal hasil ekstraksi dari asbuton tidak mengandung parafin dan sedikit kadar sulfur sehingga kualitasnya lebih tinggi

Pengolahan dengan pemanas putar (Gambar 5) dengan hasilnya berupa aspal butiran (BGA/Buton Granule Asphalt) dengan kandungan bitumen antara 20 hingga $25 \%$.

Aspal Buton dapat digunakan sebagai lapis permukaan jalan, fondasi atas jalan (asphalt treated base) dan 
fondasi bawah jalan (asphalt treated sub base) yang dapat dilakukan dengan cara campuran panas (hot mix) atau campuran dingin (cold mix).

\section{Campuran dingin (Cold Mix)}

Aspal + bahan peremaja + aggregat/pasir dicampur secara dingin di dalam Concrete Mixer, kemudian dihamparkan dan dipadatkan di jalan. Lapis Asbuton campuran dingin telah digunakan di seluruh Indonesia sebagai lapis asbuton aggregat dan lapis tipis asbuton pasir.

\section{Campuran Panas (Hot Mix).}

Asbuton + Bahan Perekat + agrergat dicampur dengan pemanasan di dalam Asphalt Mixing Plant (AMP). Pertama kali dicoba untuk pengaspalan ruas jalan Cimahi Padalarang di tahun 1956/1957, pada tahun 1972 di ruas jalan Jakarta Cikampek dan tahun 1973 di ruas jalan Banyudono Kartosuro. Untuk ruas jalan Cimahi Padalarang baru pada tahun 1978 direhabilitasi.

Produk PT. Sarana Karya terbaru adalah Buton Granular Asphalt (BGA) yaitu produk aspal alam yang siap pakai dengan mutu yang terjaga serta telah diproses sedemikian rupa sehingga bitumennya keluar ke permukaan butiran. BGA tersedia dalam kemasan karung plastik $40 \mathrm{~kg}$. BGA degan kemasan kantong jumbo ukuran 1 hingga 2 ton juga tersedia atas permintaan khusus.

BGA mengandung $25 \%$ bitumen dan berbentuk butiran halus dengan ukuran maksimum 1,2 mm.

BGA mengatasi berbagai kekurangan yang dijumpai pada asbuton seperti :

o Kehilangan (loose) yang tinggi.

o Kadar air yang tidak terjaga.

o Ukuran butiran yang relatif tidak terjaga.

o Adanya material asing (lump).

Mutu produk dapat berubah sewaktu diangkut (kadar air, ukuran butiran, cemaran).

BGA memiliki keunggulan-keunggulan dibanding produk asbuton sebelumnya yaitu :

o Kadar aspal lebih tinggi (25\%).

- Kadar air konstan di bawah $2 \%$.

o Bitumen telah termobilisasi keluar.

o Kehilangan(loose) sangat rendah.

- Material asing telah dihilangkan dalam proses.

o Produk ini dapat digunakan sebagai aditif maupun sebagai substitusi aspal.

o Mutu campuran aspal menjadi jauh lebih baik dengan harga yang ekonomis.

o Pengiriman lebih mudah.

- Perencanaan campuran mengikuti standar Hotmik.
BGA mempunyai kelebihan, yaitu ketahanan yang lebih baik terhadap deformasi. Hal ini menunjukkan bahwa penggunaan BGA di dalam campuran beraspal akan memperbaiki mutu aspal minyak sehingga perkerasan akan menjadi lebih tahan terhadap deformasi akibat beban lalu lintas.

Ketahanan terhadap temperatur tinggi. BGA di dalam campuran aspal akan meningkatkan titik lembek (dapat mencapai 5060 o C ) bitumen sehingga campuran akan lebih tahan terhadap temperatur tropis yang tinggi.

BGA dapat dipergunakan antara lain untuk pembuatan jalan raya, lapangan terbang, lapangan kontainer, seal coat, lapis penetrasi dan slurry seal.

BGA dapat digunakan untuk campuran panas (Hotmix) maupun campuran dingin (coldmix). Perencanaan campuran BGA sama dengan perencanaan campuran hotmix atau coldmix yang standar dan dikenal luas oleh material engineer. Untuk campuran panas, bahan BGA dimasukkan ke dalam Mixer Asphalt Mixing Plant (AMP) melalui elevator filler. Metode pelaksanaan sama dengan hotmix dan menghasilkan mutu campuran yang lebih baik. Untuk campuran dingin BGA dicampur deengan agregat bersama cutback' (MC 800) atau aspal emulsi dengan menggunakan pan mixer.

\section{Kandungan Minyak}

Analisis conto dilakukan untuk 7 (tujuh) buah conto aspal yang terpilih dengan menggunakan metode retort yang dilakukan di Laboratorium Fisika Mineral, Direktorat Inventarisasi Mineral Bandung.

Berdasarkan hasil analisis tersebut, menunjukkan besarnya kandungan rata-rata minyak pada conto batuan aspal yaitu 59,06 liter/ton, apabila dikalikan dengan besarnya cadangan aspal sebanyak 179,1 juta ton maka sumber daya hipotetik minyak dalam aspal buton di wilayah pertambangan aspal ini sebanyak 10.577.646.000 liter, conto tersebut diambil di Lapangan Kabungka dan Lawele.

Tabel 6. Hasil analisis kandungan minyak pada aspal

\begin{tabular}{|c|c|c|c|c|c|}
\hline \multirow{2}{*}{ No } & \multirow{2}{*}{$\begin{array}{c}\text { Nomor } \\
\text { Conto }\end{array}$} & \multicolumn{2}{|c|}{ Kandungan } & \multicolumn{2}{c|}{ Specific Gravity } \\
\cline { 3 - 6 } & $\begin{array}{c}\text { Air } \\
\text { (L/Ton) }\end{array}$ & $\begin{array}{c}\text { Minyak } \\
\text { (LTon) }\end{array}$ & Batuan & Minyak \\
\hline 1 & PW/R/01 & 50 & 50 & 1,65 & $0,85^{*}$ \\
\hline 2 & PW/R/03 & 90 & 76 & 1,29 & $0,82^{*}$ \\
\hline 3 & PW/R/04 & 39 & 32 & 1,22 & $0,87^{*}$ \\
\hline 4 & PW/R/05 & 70 & 6,7 & 1,41 & $0,83^{*}$ \\
\hline 5 & PW/R/06 & 65 & 80,7 & 1,40 & $0,81^{*}$ \\
\hline 6 & PW/R/07 & 85 & 70 & 1,45 & $0,91^{*}$ \\
\hline 7 & PW/R/11 & 55 & 98 & 1,41 & $0,80^{*}$ \\
\hline
\end{tabular}

Catatan: *Minyak + Tar 

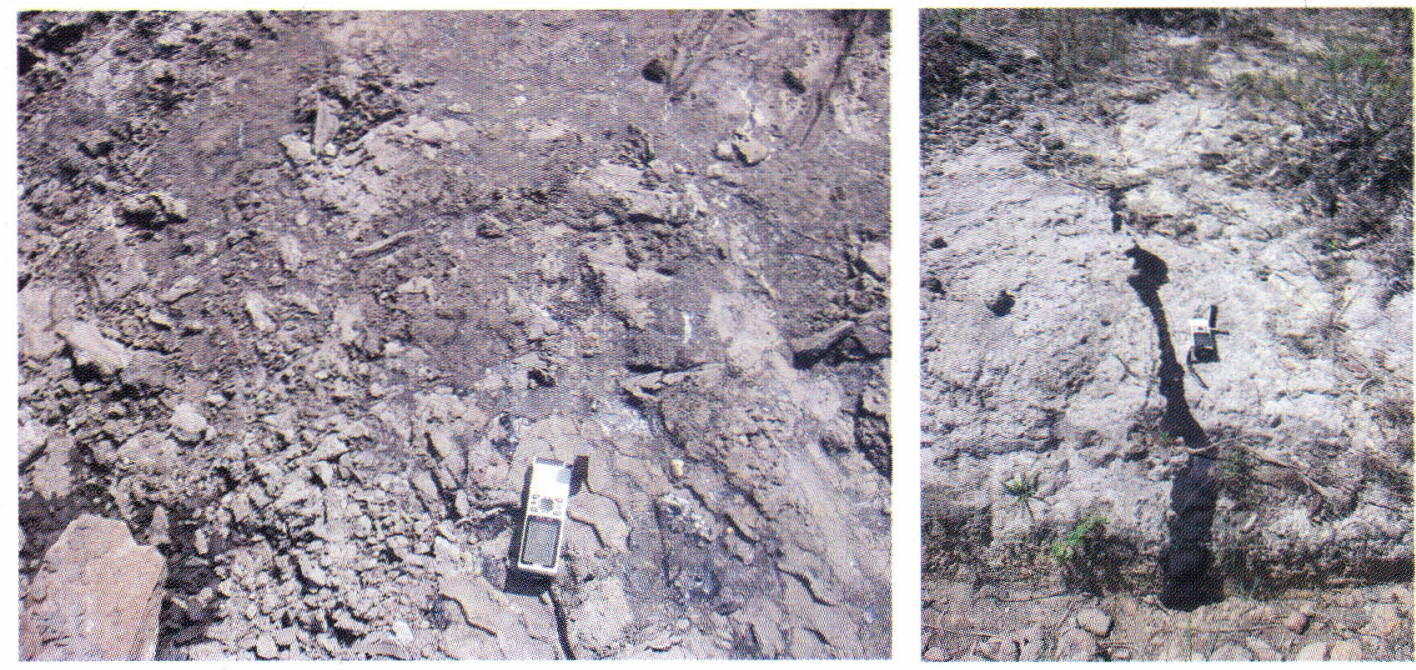

Gambar 4. Singkapan Aspal Buton di Kabungka Lapangan F (kiri),

Lelehan Aspal pada Singkapan di Kabungka Lapangan E (kanan)
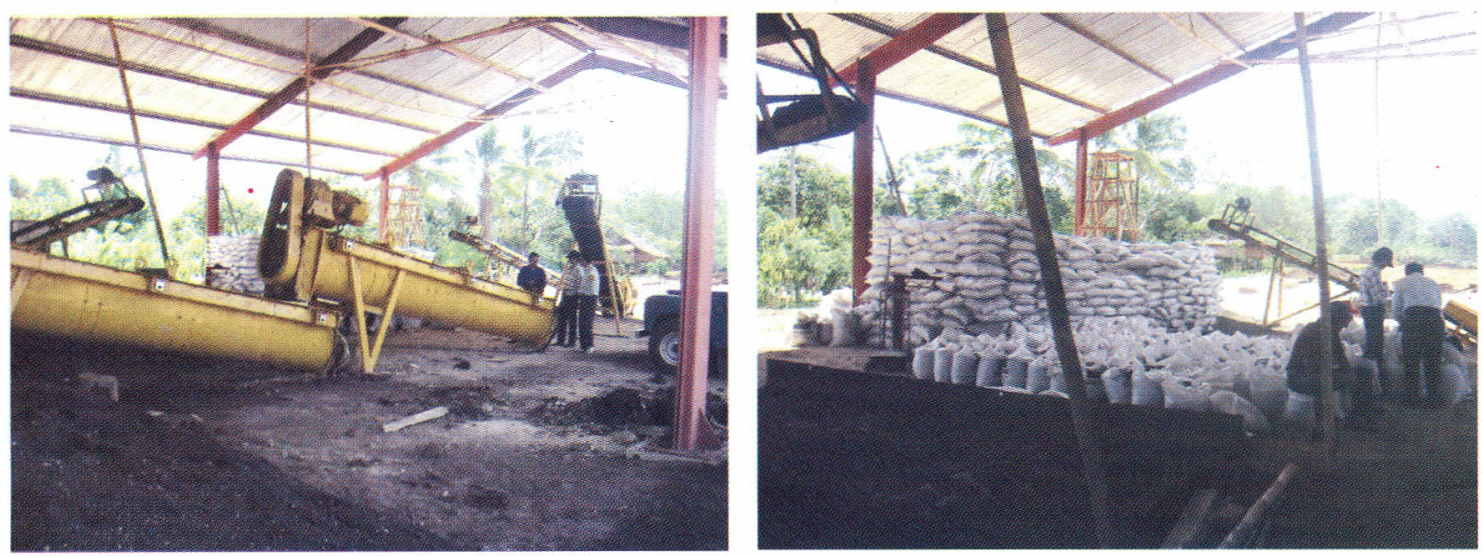

Gambar 5. Pemanas putar untuk menghasilkan BGA (kiri), BGA yang sudah di dalam karung ukuran $40 \mathrm{~kg}$, siap untuk dipasarkan (kanan)

\section{PENAMBANGAN}

Pembukaan lahan dilakukan secara bertahap, dengan perhitungan bahwa lahan yang dibuka tidak terlalu luas agar dapat mencegah erosi. Tanah pucuk yang mempunyai kandungan unsur hara (humus) yang sangat dibutuhkan tanaman dikupas terlebih dahulu dengan bulldozer sesuai dengan ketebalannya sehingga tidak tercampur dengan material lain, kemudian ditimbun di lokasi tersendiri yang selanjutnya dimanfaatkan untuk penimbunan kembali lahan bekas tambang. Lapisan tanah penutup relatif tipis pada kisaran $1,7 \mathrm{~m} 8,7 \mathrm{~m}$.

Pengupasan tanah penutup dilakukan menggunakan bulldozer yang selanjutnya ditimbun di tempat penimbunan yang telah disiapkan atau langsung ditimbun di daerah bekas tambang (back filling).

Reklamasi pada bekas tambang dilakukan dengan menimbun kembali dan penanaman kembali pada bekas timbunan dengan tanaman keras yang mudah tumbuh dan tahan terhadap kekeringan, seperti Akasia.
Untuk mengatasi longsoran yang terjadi pada daerah yang dikupas maupun bekas timbunan, dibuat jenjang sesuai dengan kondisi batuannya.

Ketebalan lapisan aspal yang sudah ditambang antara $1,0 \mathrm{~m} 10 \mathrm{~m}$, menurut hasil pemboran ketebalan lapisan aspal di semua lapangan bervariasi 2,5 m sampai dengan $11 \mathrm{~m}$. Stripping ratio pada kisaran $0.39: 1$. Rata-rata Stripping Ratio penambangan yaitu 0,48 : 1 . Hal menunjukkan bahwa penambangan aspal relatif mudah.

\section{BAHAN GALIAN LAIN}

Endapan aspal terdapat di dalam batu gamping Formasi Sampolakosa yang merupakan hasil impregnasi ke dalam batuan di sekelilingnya atau yang dilaluinya.

Batugamping merupakan bahan galian lain yang umum terdapat di Kecamatan Pasarwajo. Potensi ini ditunjukkan dengan pelamparan yang luas pada Formasi Sampolakosa. Keterdapatan batugamping dapat ditemukan di sepanjang jalan antara Baubau Pasar Wajo di daerah sekitar km 22 dari Baubau sebelum jembatan sungai 

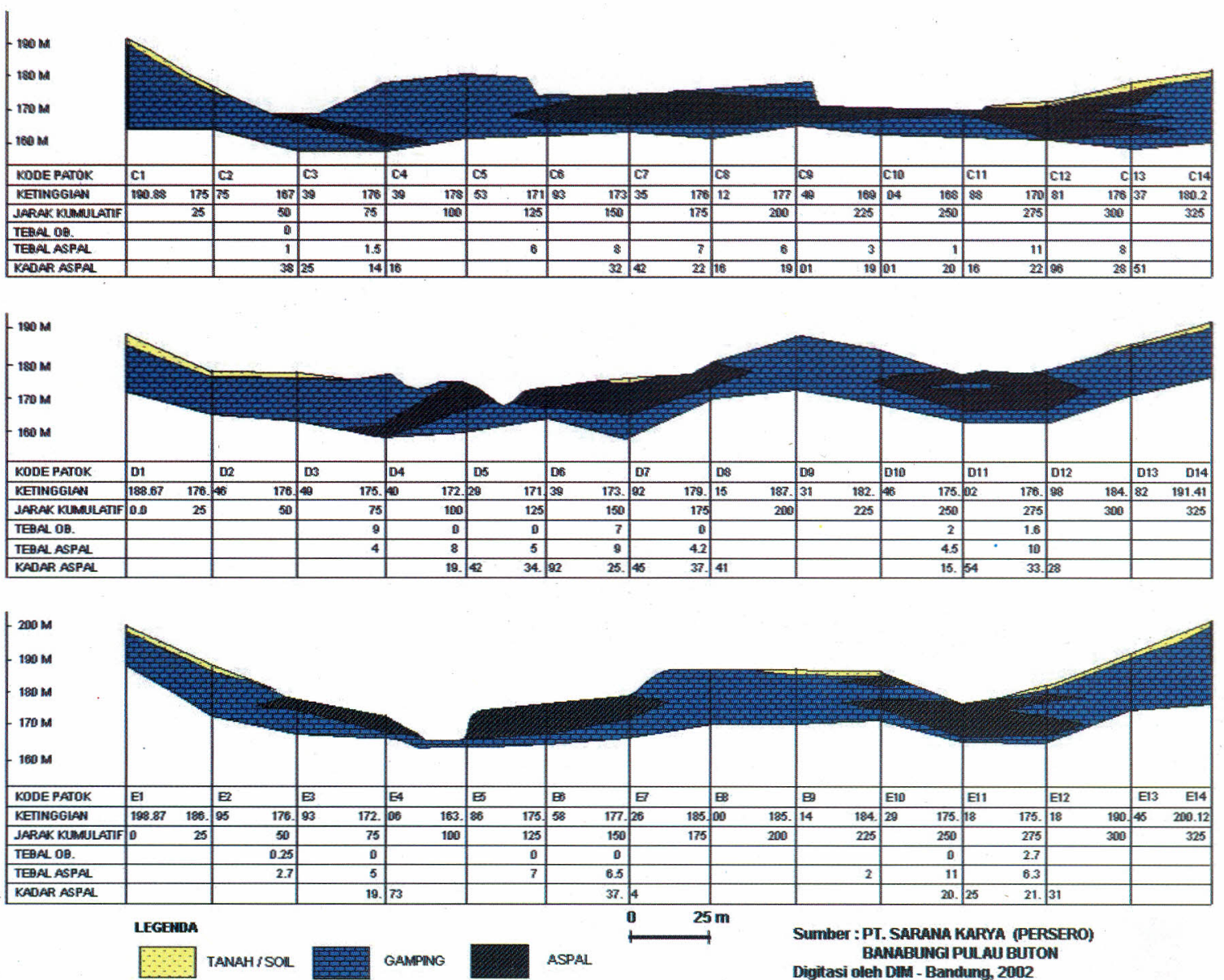

Gambar 6. Penampang litologi hasil pemboran inti di lapangan Galababi (Sumber data PT. Sarana Karya)

Kaongkeongkea, saat ini banyak digunakan untuk material campuran bangunan atau pembuatan batubata (Gambar 8).

Hasil analisis conto batugamping di beberapa tempat diperoleh nilai rata-rata $\mathrm{CaO}$ sebesar 52,23\% dengan kadar $\mathrm{MgO}$ rata-rata $1,49 \%$ hal ini menunjukkan bahwa batugamping tersebut memenuhi syarat kualitas untuk bahan baku semen portland, oleh karena itu perlu dipertimbangkan pemanfaatan yang optimal yang sesuai dengan spesifikasi bahan galian agar memiliki nilai tambah yang tepat.

Penambangan aspal buton dilakukan dengan metode tambang terbuka, dengan menggali tanah penutup dan batuan di atasnya termasuk batugamping tersebut. Oleh karena itu perlu direncanakan penanganan batugamping yang terganggu karena proses penambangan tersebut. Menempatkan batugamping di suatu tempat atau memanfaatkannya merupakan hal yang perlu ditempuh agar optimal dalam pengelolaan bahan galian. Apabila batugamping tersebut belum dimanfaatkan maka perlu disimpan di suatu tempat tertentu yang tidak akan mengurangi kualitas bahan galian tersebut.

\section{BAHAN GALIAN TERTINGGAL}

Dalam proses penambangan bahan galian umumnya tidak semua sumber daya dan cadangan dapat ditambang karena beberapa faktor yang mempengaruhinya antara lain keterbatasan teknologi, kondisi sosial, geologi dan pemasaran, hal ini disebut sebagai sisa sumber daya dan cadangan atau bahan galian tertinggal.

Adapun dari sisa cadangan bahan galian asbuton yang ada pasca penambangan saat ini antara lain :

o Asbuton dengan kualitas kandungan bitumen rendah.

o Asbuton yang tidak dapat ditambang karena kondisi geologi setempat.

o Asbuton yang tidak dapat ditambang karena sudah berada di bawah permukaan laut.

Upayaupaya penanganannya seperti di daerah bekas tambang dilakukan penimbunan dan reklamasi dengan cara tertentu yang apabila pada suatu saat mempunyai nilai ekonomi dapat diusahakan kembali dengan proses penggalian lebih mudah. 


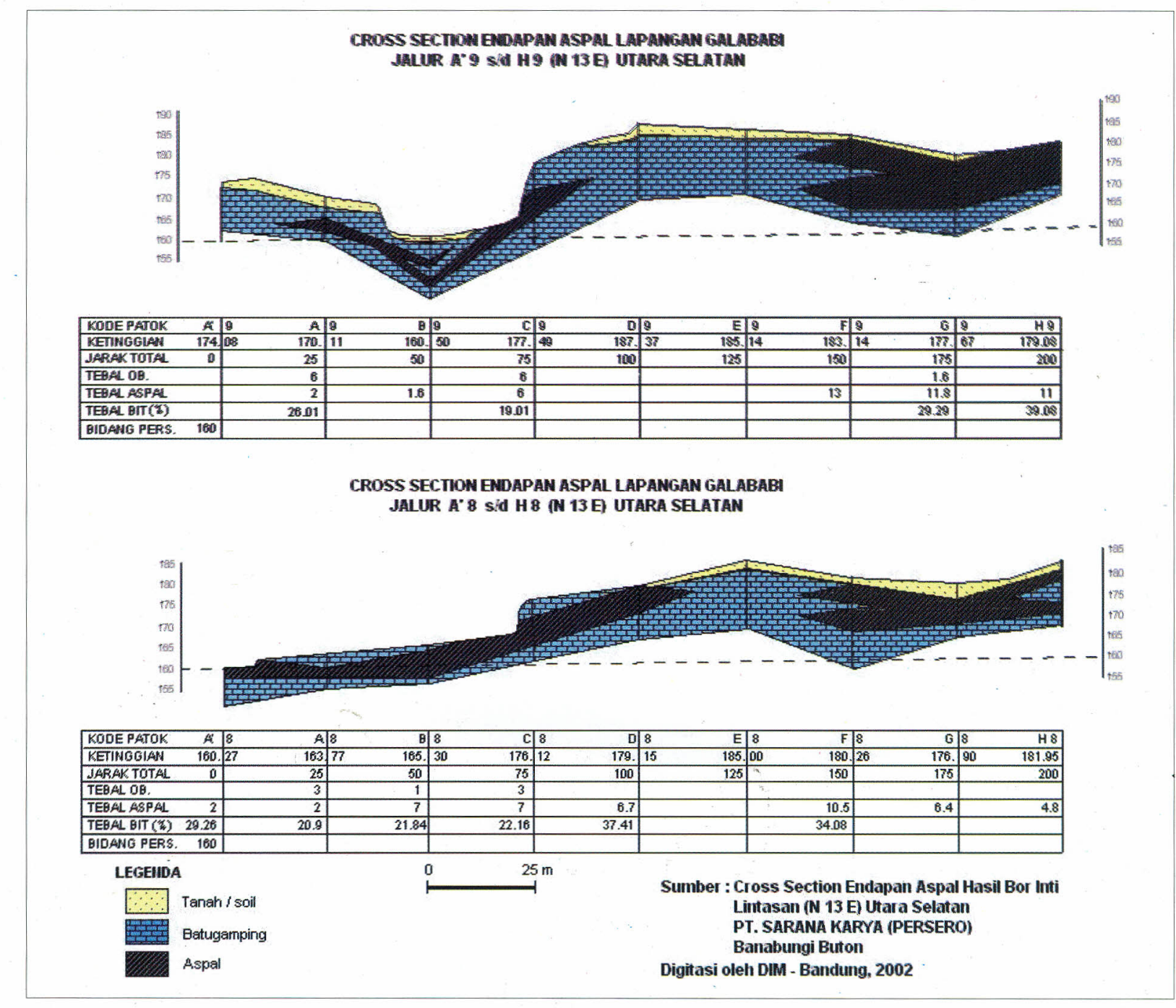

Gambar 7. Penampang endapan Aspal di Lapangan Galababi Winto (Sumber data PT. Sarana Karya)

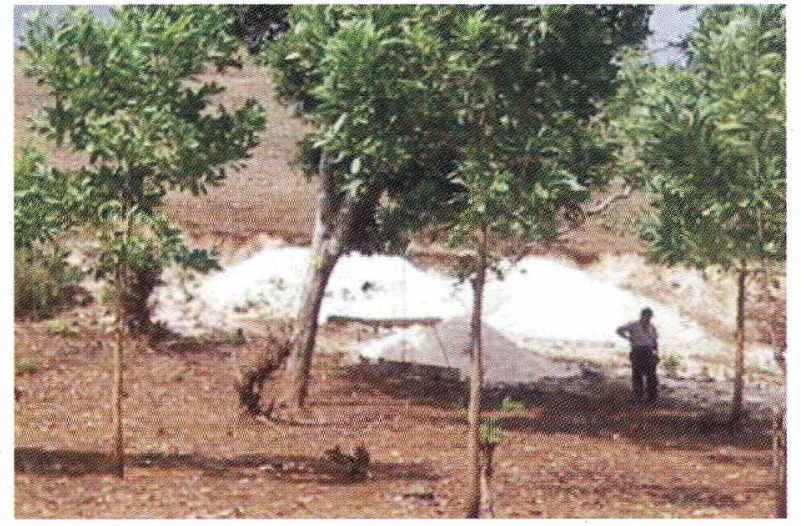

Gambar 8. Batugạmping di sekitar Kaongkeongkea $\mathrm{km} 22$ dari Baubau

\section{KESIMPULAN}

Berdasarkan data hasil pemboran eksplorasi, cadangan aspal buton di pada wilayah konsesi PT. Sarana Karya sebesar 184 juta ton sedangkan jumlah produksi sejak tahun 1926 sampai 2002 tercatat sebanyak 4,9 juta ton, hal tersebut menunjukkan cadangan tersisa masih sangat besar yaitu 179,1 juta ton. Sumber daya hipotetik minyak pada aspal buton tersebut sebanyak 10.577.646.000 liter.
Penambangan aspal relatif mudah, cukup dengan rata-rata stripping ratio $0,48: 1$.

Dari segi kualitas, produk berupa Buton Granular Asphalt(BGA) memiliki beberapa kelebihan, seperti :

o Ketahanan deformasi yang lebih baik. Hal ini menunjukkan bahwa penggunaan BGA di dalam campuran beraspal akan memperbaiki mutu aspal minyak sehingga perkerasan akan menjadi lebih tahan terhadap deformasi akibat beban lalu lintas.

$\because$ Ketahanan terhadap temperatur tinggi, BGA di dalam campuran aspal akan meningkatkan titik lembek bitumen (sekitar 5060 o C) sehingga campuran akan lebih tahan terhadap temperatur tropis yang tinggi.

Pengembangan BGA dapat memberikan peningkatan kualitas dan nilai manfaat aspal buton.

Aspal buton umumnya terdapat dalam batuan induk berupa batugamping, apabila dilakukan penambangan aspal maka harus mempertimbangkan pemanfaatan/penanganan batugamping yang ikut tergali atau terganggu. 
Potensi batugamping yang relatif berlimpah dan memenuhi syarat kualitas bahan baku semen portland potensial untuk dikembangkan.

Adanya kandungan minyak dalam aspal buton merupakan alternatif pemanfaatan bahan galian tersebut selain untuk bahan konstruksi. Dengan harga minyak yang membumbung tinggi, maka penggunaan aspal dengan mengolah menjadi minyak merupakan alternatif pemanfaatan yang semakin prospektif untuk mendapatkan nilai tambah yang lebih optimal.

\section{UCAPAN TERIMA KASIH}

Ucapan terimakasih disampaikan kepada Ir. Sabtanto Joko Suprapto Koordinator Kelompok Program Penelitian Konservasi, Pusat Sumber Daya Geologi yang telah mendorong tim penulis untuk menyusun makalah ini.

\section{ACUAN}

Abdul Rosyid, 1998. Pertambangan Aspal Alam Pulau Buton, PPTM, Bandung

AJM, 1999. Operating Mines (CoW and KP) Asian Journal Mining, Indonesia Mineral Exploration and Mining, Directory 1999/ 2000, p.199-200.

Hardjono, 1966. Laporan Singkat Tentang Hasil Eksplorasi Endapan Aspal di Lapangan D dan E Daerah Kabungka Buton, Sulawesi Tenggara, Direktorat Geologi, Bandung.

Sikumbang, N, Sanyoto.P, Supandjono, R.J.B dan Gafoer.S, 1995. Peta Geologi Lembar Buton, Pusat Penelitian dan Pengembangan Geologi, Bandung, Sekala 1 :250.000.

Subarnas, S, dkk, 2001. Penyelidikan Pendahuluan Endapan Bitumen Padat Di Daerah Pasarwajo Dan Sekitarnya, Kabupaten Buton, Propinsi Sulawesi Tenggara, DIM, Bandung.

Suhala, S, Sudradjat A, Mulyono, 1996. Bahan Galian Industri, PPTM, Bandung.

Suryana, A., Tobing, S.M, 2002. Inventarisasi Endapan Bitumen Padat dengan Outcrop Drilling di Daerah Buton Selatan, Kabupaten Buton, Provinsi Sulawesi Tenggara, Sub Dit Batubara, DIM, Bandung

Tobing, S.M, 2003. Prospek Bitumen Padat di Pulau Buton, Sulawesi Tenggara, Sub Dit Batubara, DIM, Bandung

Tobing, S.M, 2005. Inventarisasi Bitumen Padat di Daerah Sampolawa, Kabupaten Buton, Sulawesi Tenggara, Sub Dit Batubara, DIM, Bandung

http:/members.tripod.com/sultra/ASPAL_BUTON.htm 